\title{
The Absolute Configuration of Isoancistrocladine and 'Isohamatine' by Quantumchemical CD-Calculations
}

\author{
J. Fleischhauer, A. Koslowski, Ch. Repges, K.-P. Gulden ${ }^{\mathrm{a}}$, G. Bringmann ${ }^{\mathrm{a}}$ \\ Institut für Organische Chemie, RWTH Aachen, Prof.-Pirlet-Str. 1, D-52074 Aachen \\ a Institut für Organische Chemie, Universität Würzburg, Am Hubland, D-97074 Würzburg \\ Z. Naturforsch. 53 a, 993-996 (1998); received November 3, 1998 \\ The absolute configuration of the naphthylisoquinolines isoancistrocladine and isohamatine at the \\ biaryl axis was determined by comparing the measured and the calculated CD spectra. \\ In order to calculate these spectra we used the CNDO/S method in combination with a Boltzmann \\ weighting of conformers with different dihedral angles at the biaryl axis. The Boltzmann factors were \\ obtained with the AM1 method.
}

Key words: Circular Dichroism; Biaryls; CNDO/S Method; AM1 Method.

\section{Introduction}

Among the alkaloids, the naphthylisoquinolines constitute a rapidly growing class of structurally, biosynthetically active products [1 - 6], of which important representitives are ancistrocladine (1a) and hamatine (1b).

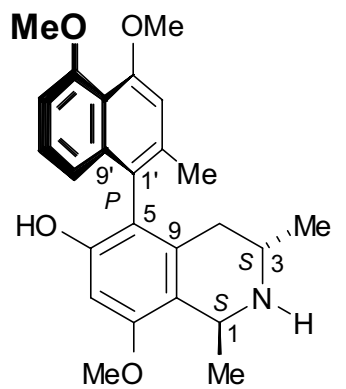

1a

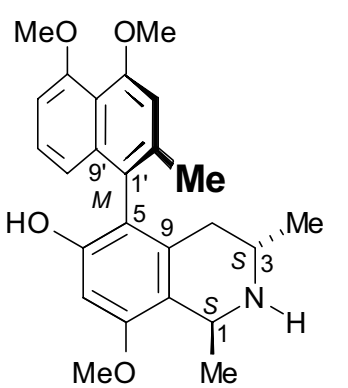

1b
Fig. 1. Stereostructures of ancistrocladine (1a) and hamatine (1b).

Besides the two stereogenic centers located in the isoquinoline part, there is a biaryl axis as a further structural element such that $\mathbf{1 a}$ and $\mathbf{1 b}$ actually form two atropo-diastereoisomers. In order to effectively optimize and finally use the properties of these alkaloids, the elucidation of their absolute stereostructure

Reprint requests to Prof. Jörg Fleischhauer; Fax: +49241 8888385; E-mail: gk016fl@ @luster.rz.rwth-aachen.de. is an important requirement. Regarding ancistrocladine (1a), one of the most widespread naphthylisoquinoline alkaloids [1], we have established a theoretical procedure for the calculation of CD spectra as an efficient analytic tool for the elucidation of the absolute stereostructure at the biaryl axis [7], and we have subsequently applied it to a broad variety of further related but also structurally most different chiral compounds [8,9]. Another diastereomer of ancistrocladine (1a) is the C1-epimeric and thus cisconfigured related alkaloid, isoancistrocladine (2a), an oxidation-sensitive, and thus relatively unstable compound, recently isolated from the tropical liana, A. heynenaus [10].

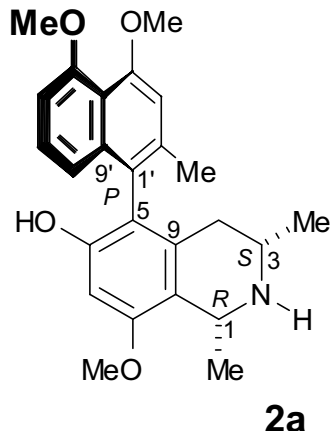

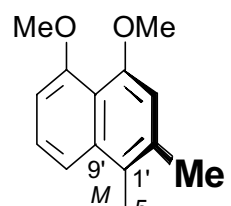

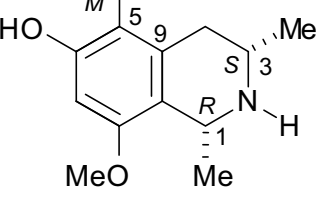
2b

Fig. 2. Structures of isoancistrocladine (2a) and isohamatine (2b).

In its isoquinoline part it is $R$-configured at $\mathrm{C} 1$ and $S$-configured at C3. Its absolute axial configuration

0932-0784 / 98 / 1200-0993 \$06.00 (c) Verlag der Zeitschrift für Naturforschung, Tübingen · www.znaturforsch.com 


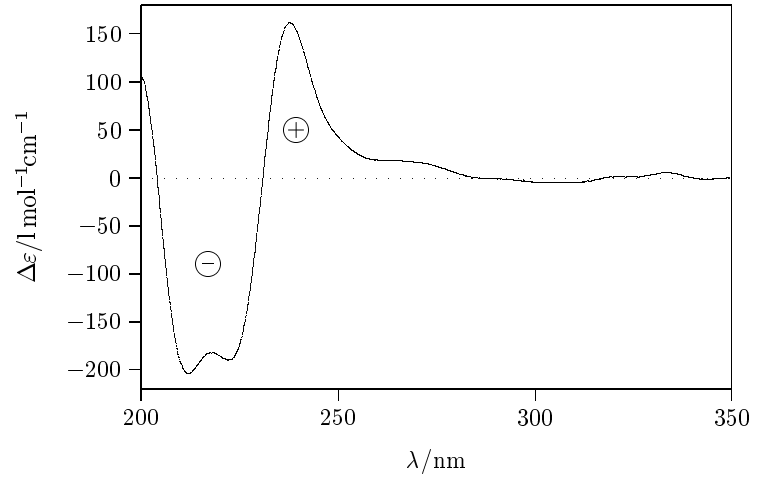

Fig. 3a. Experimental CD spectrum of isoancistrocladine (2a) in ethanol.

has as yet been proven only by comparing its $\mathrm{CD}$ spectrum with that of the related, but $1 S$-configured and thus diastereometric compound (1a), and by synthesis [10].

In this paper we describe the attribution of the absolute stereostructure of isoancistrocladine and the as yet unkown 1-epimer of hamatine ('isohamatine') (2b), by quantummechanical calculation of their $\mathrm{CD}$ spectra, and comparison with the experimental ones.

\section{Materials and Methods}

Samples of isoancistrocladine (2a) and isohamatine (2b) were available from previous isolation and synthetic work in our group [10,11, 12]. Their CD spectra (from 350 to $200 \mathrm{~nm}$ ) were measured on a JOBIN YVON Model CD6 Spectrograph at room temperature, in ethanol as solvent, and are shown in Figs. 2a and 2b.

As already described in earlier papers [7,8], we perform the geometry optimization and the calculation of the CD spectra of isoancistrocladine (2a) and isohamatine (2b) using the semiempirical method AM1 [13] included in the program package MOPAC 6.0 [14]. Starting from the structures containing bond lengths and bond angles taken from the literature [15], we calculated the global energetic minimum structure by optimizing all internal coordinates, i.e. bond lengths, bond angles, and dihedral angles.

As the CD behaviour of a biaryl compound does not only depend on its formal absolute configuration, but also strongly on the conformation at the biaryl axis [16], several structures with different biaryl dihedral angles have to be taken into account. These

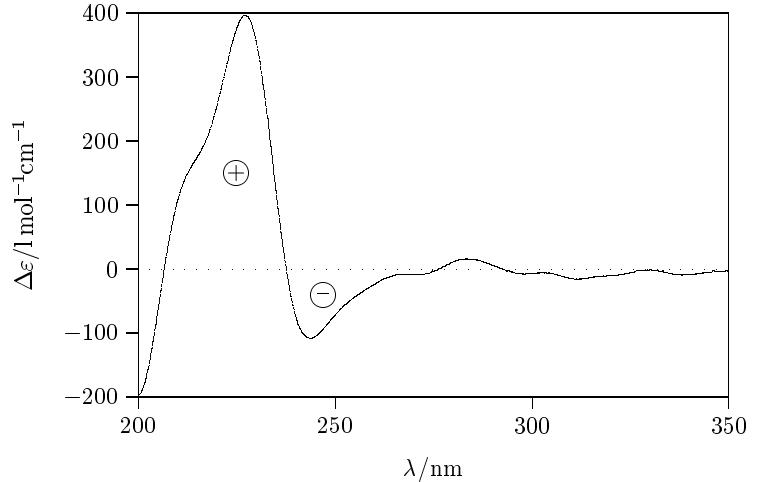

Fig. 3b. Experimental CD spectrum of isohamatine (2b) in ethanol.

were generated by varying the biaryl dihedral angle 9-5-5' -9 ' of the energetic minimum structures (here for 2a and 2b) in steps of several degrees, then fixing this angle and again optimizing all other internal coordinates. By plotting the resulting heats of formation against the dihedral angle, the potential curve for each compound was obtained.

Then for each structure the corresponding single $\mathrm{CD}$ spectrum was calculated using the semiempirical method CNDO/S [17] as implemented in the program package DZDO/MCD3SP [18].

In the CI calculation we used 169 singly exited singulet configurations, resulting from the excitation of one electron from one of the thirteen highest occupied into one of the thirteen lowest unoccupied molecular orbitals. The rotational strengths were obtained using the origin-independent dipole-velocity formalism and were multiplied with gaussian functions with the following exponential halfbandwidths: $6.02 \mathrm{~nm}$ for the transition below $180 \mathrm{~nm}, 6.72 \mathrm{~nm}$ for transitions between $180 \mathrm{~nm}$ and $235 \mathrm{~nm}$ and $7.68 \mathrm{~nm}$ for transitions above $235 \mathrm{~nm}$. Finally, the total spectrum of each compound was obtained by adding the single spectra after Boltzmann weighting them at a temperature of $298 \mathrm{~K}$ using the heats of formation of the corresponding structures.

\section{Results}

\section{Measured CD Spectra}

The experimental CD spectra of the two compounds isoancistrocladine (2a) and isohamatine (2b) are presented in Figs. 3a and 3b. 


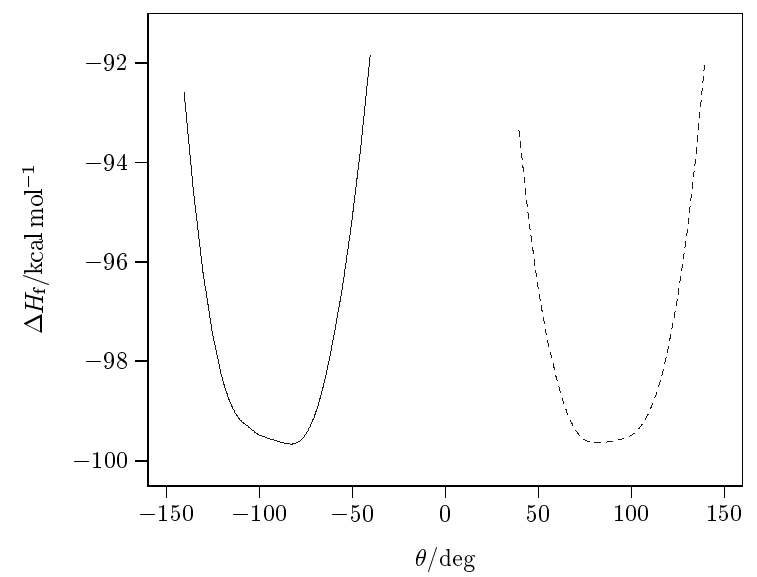

Fig. 4. Potential curves of isoancistrocladine (-) and isohamatine (- - ).

The spectrum presented in Fig. 3a reveals a broad negative double peak in the area between 210 and $230 \mathrm{~nm}$ and smaller and less intensive peak at about $240 \mathrm{~nm}$. Another positive peak appears in the shortwave part of the spectrum. The spectrum presented in Fig. $3 b$ shows similar peaks, but with opposite signs. The double peak is less pronounced; and at $210 \mathrm{~nm}$ it offers only a shoulder.

\section{Optimization of the Geometry}

Figure 4 presents the potential curves obtained by optimizing the geometry of the different conformers for stepwise varied, but fixed biaryl dihedral angles and plotting the resulting heat of formation against the corresponding angle.

As the atropisomeric compounds $\mathbf{2 a}$ and $\mathbf{2 b}$ are diastereomeric - not enantiomeric - to each other, the two curves do not behave like mirror images. Both potential curves have a minimum located at $-82.3^{\circ}$ for $\mathbf{2 a}$ and at $81.6^{\circ}$ for $\mathbf{2 b}$. In the neighborhood of this minimum both curves are very flat, indicating a high rotational flexibility for the near-orthogonal ring systems.

\section{Calculated CD Spectra}

Figures $5 \mathrm{a}$ and $5 \mathrm{~b}$ present the entire spectra of isoancistrocladine (2a) and isohamatine (2b) respectively, as calculated according to the method described in Part 2.

It turns out that all major peaks of the calculated spectra are shifted by $10-20 \mathrm{~nm}$ to longer wavelengths

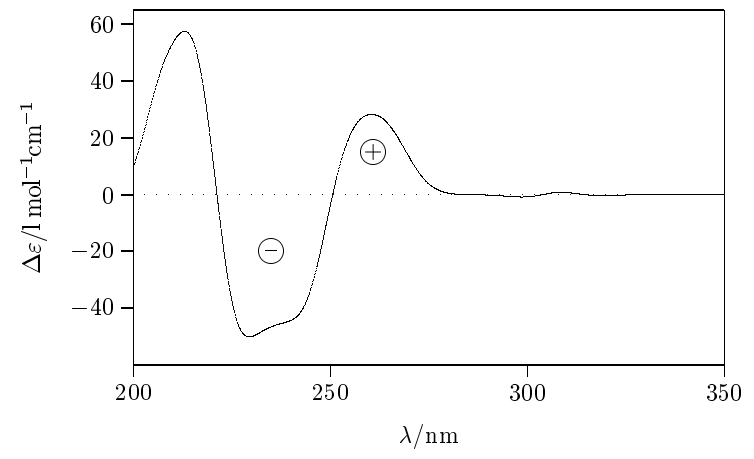

Fig. 5a. Calculated CD spectrum of isoancistrocladine (2a).

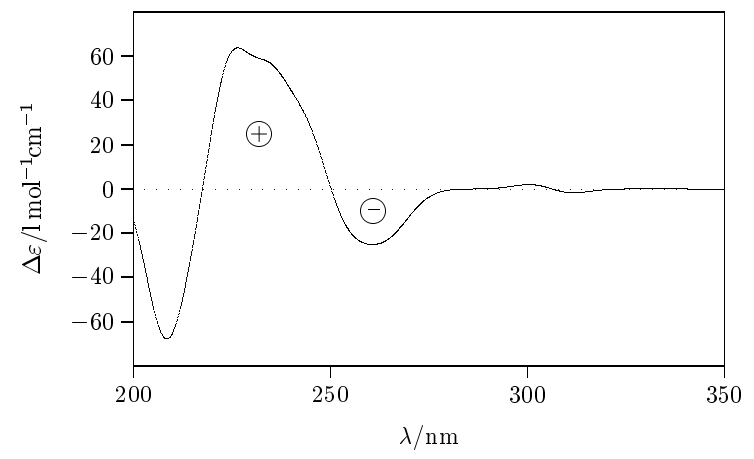

Fig. 5b. Calculated CD spectrum of isohamatine (2b).

as compared with the measured ones, which was also observed and discussed in previous work [7 - 9]. The calculated spectrum of isoancistrocladine (Fig. 5a) agrees with the experimental one (Fig. 3a) with regard to the sign of the major peak, and so do the two spectra of isohamatine, Figs. $3 \mathrm{~b}$ and $5 \mathrm{~b}$. The negative double peak of the experimental spectrum of isoancistrocladine (2a) is only reproduced by a flat shoulder, and the positive double peak in the calculated spectrum of isohamatine has a shoulder apparently higher and on the opposite side as compared with the corresponding measured spectrum in Figure 3b.

The allocation of the two experimental spectra of the two diastereomers however is unique. The comparison of the experimental and the quantumchemically calculated ones of the two alkaloids clearly establishes their absolute axial configurations.

\section{Acknowledgement}

The authors gratefully acknowledge financial support by the Deutsche Forschungsgemeinschaft (Normalverfahren Fl 142/4-1 'CD/Biaryl' and Sonderfor- 
schungsbereich 347 'Selektive Reaktionen Metall-aktivierter Moleküle') and by the Fonds der Chemischen Industrie.

[1] G. Bringmann and F. Pokorny; in The Alkaloids, vol.46, (Ed.: G. A. Cordell), Academic Press, New York, 1995, 127-271.

[2] G. François, M. Van Looveren, G. Timperman, B. Chimanuka, L. Aké Assi, J. Holenz, and G. Bringmann; J. Ethnopharmacol. 54, 125 (1996).

[3] G. François, G. Bringmann, J. D. Phillipson, L. Aké Assi, C. Dochez, M. Rübenacker, C. Schneider, M. Wéry, D. C. Warhurst, and G. C. Kirby; Phytochemistry 35, 1461 (1994).

[4] G. François, G. Timperman, J. Holenz, L. Aké Assi, T. Geuder, L. Maes, J. Dubois, M. Hanocq, and G. Bringmann; Ann. Trop. Med. Parasitol. 90, 115 (1996).

[5] G. François, G. Timperman, W. Eling, L. Aké Assi, J. Holenz, and G. Bringmann; Antimicrob. Agents Chemother. 41, 2533 (1997).

[6] M. R. Boyd, Y. F. Hallock, J. H. Cardellina II, K. P. Manfredi, J. W. Blunt, J. B. McMahon, R. W. Buckheit Jr., G. Bringmann, M. Schäffer, G. M. Cragg, D. W. Thomas, and J. G. Jato; J. Med. Chem. 37, 1740 (1994).

[7] G. Bringmann, K.-P. Gulden, H. Busse, J. Fleischhauer, B. Kramer, and E. Zobel; Tetrahedron 49, 3305 (1993).

[8] J. Fleischhauer, A. Koslowski, B. Kramer, E. Zobel,
G. Bringmann, K.-P. Gulden, T. Ortmann, and B. Peter; Z. Naturforsch. 48b, 140 (1993).

[9] G. Bringmann, K.-P. Gulden, Y. F. Hallock, K. P. Manfredi, J. H. Cardellina II, M. R. Boyd, B. Kramer, and J. Fleischhauer; Tetrahedron 50, 7807 (1994).

[10] G. Bringmann, B. Kinzinger, T. Ortmann. and N. J. de Souza; Phytochemistry 35, 259 (1994).

[11] G. Bringmann, L. Kinzinger, Phytochemistry 31, 3297 (1992).

[12] G. Bringmann, T. Geuder, F. Pokorny, M. Schäffer, and R. Zagst; Planta Med. 59 (Suppl.), 619 (1993).

[13] M. J. S. Dewar, E. G.Zoebisch, E. F. Healy, and J. J. P. Stewart; J. Am. Chem. Soc. 107, 3902 (1985).

[14] J. J. P. Stewart, MOPAC: A General Molecular Orbital Package (Version 6.0); Quant. Chem. Progr. Exch. 9, 455 (1990).

[15] J. A. Pople, D. L. Beveridge, Approximate Molecular Orbital Theory, McGraw-Hill, New York 1970.

[16] F. F. Mason, R. H. Seal, D. R. Roberts, Tetrahedron 30, 1671(1974) .

[17] J. Del Bene and H. H. Jaffé; J. Chem. Phys. 48, 1807 (1968).

[18] The programs DZDO and MCD3SP were written by J. Downing and J. Michl, University of Colorado at Boulder. 